\title{
Congenital pleuro-pericardial cysts
}

\author{
PH. DE ROOVER, JEAN MAISIN, AND A. LACQUET \\ From St. Raphael's Surgical Clinic and the Laboratory of Experimental Pathology, University of Louvain, Belgium
}

Most mediastinal cysts are congenital, and histologically their congenital origin can be traced in many cases, e.g., dermoid cysts, thymus cysts, pulmonary cysts. Due to mass examinations they are found in a larger proportion of patients nowadays, but often they are related to only a very vague clinical picture, if any. Diagnosis is not always easy, though most important with regard to subsequent therapy.

Pleuro-pericardial cysts occupy a particular place among these congenital diseases. They are found in the literature under various names: le kyste pleuropéricardique (Jeaubert de Beaujeu, 1945; Roche, 1954), pleural cyst, pericardial cyst, pericardial coelomic cyst (Lambert, 1940), springwater cyst (Greenfield, Steinberg, and Touroff, 1943), mesothelial cyst (Churchill and Mallory, 1937), and thin-walled cyst.

The patients treated in our department were not found on mass examination.

\section{CASE REPORTS}

CASE 1 B. L., 56 years old, had infiuenza in February 1957 , and found that he had become asthmatic. On examination in the department of internal medicine radiographs showed a large opacity in the antero-superior mediastinum. On admission the patient was asthmatic and felt weak, but he had a good appetite. In 1955 he had a cold and radiologically the upper mediastinum at that time was found to be slightly enlarged, especially to the right. On that occasion he recovered without complications.

Clinically the patient displayed a thorax of the rachitic type, and behind the upper margin of the sternum, the top of a retrosternal tumour, which moved on swallowing, could be distinctly palpated with the fingertips. Radiologically, the opacity, which was not very dense, covered almost all of the superior mediastinum.

A pneumomediastinum showed this mass not to be attached to the aorta. In order to make sure that no aneurysm was present, an angiocardiogram was taken which showed the aorta to be normal. The iodine fixation test was normal, but the basal metabolism was slightly increased. The lung function tests gave the following results: Vital capacity $2,940 \mathrm{ml}$. and maximum minute ventilation or breathing capacity $62 \%$ of normal. The electrocardiogram was normal. The blood picture and sedimentation rate were also normal.

A sternotomy was performed under a general anaesthetic on 10 May 1957. Between the manubrium sterni and the base of the heart there was a soft cystic mass, almost two fists in size. The upper pole was more or less pedunculated and reached to the upper margin of the

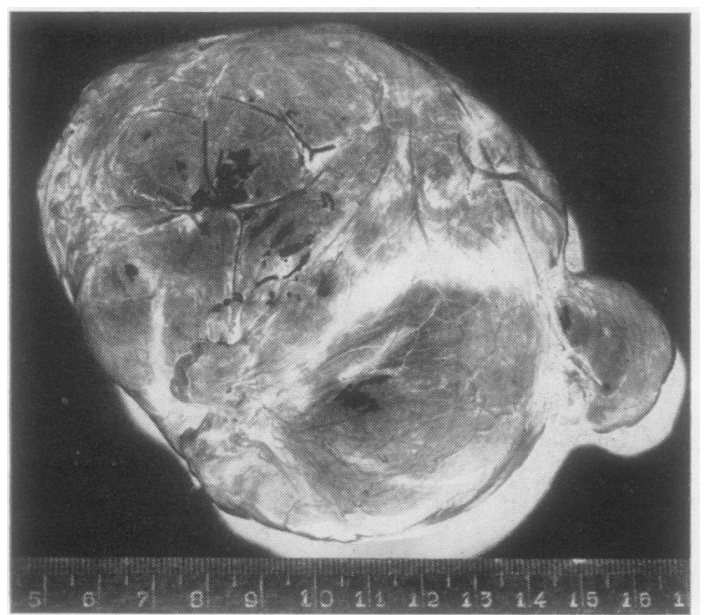

FIG. 1. Case 1. The cyst.

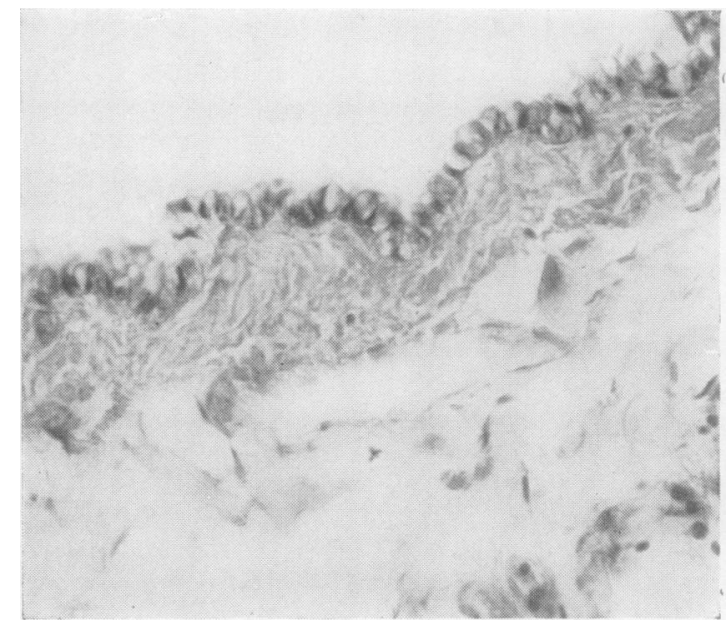

FIG. 2. Case 1. Section of the cyst wall. 
manubrium sterni, where it was clinically palpable. The tumour was easily extirpated and weighed $250 \mathrm{~g}$. Macroscopically it was nearly transparent and contained a water-like fluid (Fig. 1).

Histologically, a fibrous wall was found, with a layer of juxtaposed flattened and cuboid cells. There were no muscle fibres or lymphoid infiltrations (Fig. 2). This anatomo-pathological picture was in agreement with the description of 'pericardial coelomic cysts' given by Lambert (1940).

Post-operative recovery was rapid. Three months after the operation the patient was seen again and found to be in excellent condition. The asthma had disappeared.

CASE 2 De B. G., 52 years old, had experienced pain in the left hemithorax on deep inspiration four years previously; the pain radiated as far as the splenic area. Early in 1959 he found that he tired quickly and again felt the pain in the left hemithorax when breathing deeply. He did not feel fit and radiologically a tumour was found in the left chest and the anterior mediastinum. He was admitted.

Clinically, dullness was found at the base of the left lung. Bronchography showed the growth to be extrabronchial. An electrocardiogram was normal. The lung function tests gave the following results: Vital capacity $3,100 \mathrm{ml}$, and maximum minute ventilation or breathing capacity $119 \%$ of normal value. The blood picture was normal.

On 21 December 1959 a thoracotomy was performed under a general anaesthetic. A large ovoid tumour was found. It was a transparent, taut, pleuro-pericardial cyst which contained colourless fluid. Post-operative recovery was rapid, though lung expansion was impeded by severe pachypleuritis which was ultimately corrected to some extent by decortication.

CASE 3 V. O.-P., 44 years old, had a general medical examination in December 1959 and a radiograph showed a round shadow at the base of the left chest. She had no complaints. In April 1955 a radiograph of the chest had been taken elsewhere because of discomfort on the left side and dyspnoea; it showed some enlargement of the heart. Clinically there was hypertension, $180 / 120 \mathrm{~mm} . \mathrm{Hg}$, for which treatment was begun. The patient soon recovered and even after the incidental discovery of a pathological lesion in the chest in December 1959 she waited until July 1960 for a thorough examination; after this she was admitted.

Clinically there were no abnormalities found in the heart or lungs. The blood pressure was $130 / 70 \mathrm{~mm}$. $\mathrm{Hg}$. Radiographic examination disclosed a round benign tumour with sharp delimitation at the left base of the chest, anteriorly located, of the same size as in December 1959. Blood and urine analyses as well as bronchoscopy were normal. Lung function tests gave the following results: Vital capacity $2,065 \mathrm{ml}$. or $74 \%$ of normal; one minute expiration $69 \%$ of vital capacity; maximum minute ventilation or M.B.C. 431 . or $68 \%$ of the theoretical normal value. The electrocardiogram showed some diffuse disturbances of repolarization.
Left thoracotomy through the sixth intercostal space was performed on 29 July 1960 and a large pericardial cyst was removed. It was covered by the lingula and was adherent to the pericardium on a broad surface, so that the phrenic nerve, which could be preserved, ran on the lateral side of the cyst. There was no communication between the cavity of the cyst and the inside of the pericardium.

Post-operative recovery was uneventful.

The cyst was unilocular and contained clear water. Its wall was very thin endothelium; in scme places there was a stratif.ed epithelial covering with a mesothelial appearance.

Comment The interest of this case lies in the fact that the diagnosis of pericardial cyst might have been overlooked, because tomography suggested that there was separation between the heart shadow and the medial wall of the tumour. However, when there is no abnormal fluid density in the pericardial cavity, the contour of the heart shadow depends on the heart muscle, while the pericardium may be lifted up some distance by an adherent cyst. We saw other cases where the diagnosis of pericardial cyst had been previously rejected because of this erroneous interpretation of a tumour being separated from the heart shadow and even independently mobile.

We thought it was of interest to report these three cases because congenital pericardial cysts are fairly rare, and a location in the superior mediastinum is very rare, $\pm 1 \%$.

\section{INCIDENCE}

Ringertz and Lidholm (1956) showed that largescale radiological examinations revealed a great many mediastinal tumours without any clinical sign being present. They treated 155 mediastinal growths between 1944 and 1954. In 95 cases (61\%) the patients had had no complaints prior to radiography, though $28 \%$ of the tumours were found to be malignant on histological examination.

Congenital thoracic cysts include thyroid and thymus cysts, pericardial cysts, oesophageal or gastrogenic cysts, bronchial or pulmonary cysts, lymphoid cysts or cystic hygromas, and dermoid cysts. The proportion of pleuro-pericardial cysts is between 4 and 7\%: Roche, 1957 (7\%); Key, 1954 $(4 \%)$; Nelson, Shefts, and Bowers, 1957 (9 cases out of 125).

In 1952 Loehr classified pericardial cysts into true, acquired, and pseudo-cysts, but we have found no figures with regard to the incidence of congenital pleuro-pericardial cysts as compared with the other types.

About one in every 100,000 of the population may have a pericardial cyst (Le Roux, 1959). 
SITE

Pleuro-pericardial cysts are found primarily in the antero-inferior mediastinum where they fill the right cardiophrenic angle between the pleura and the pericardium.

Grundmann, Fischer, and Griesser (1954) reviewed 91 cases from the literature and found the following distribution: right cardiophrenic angle, $51 \%$; left cardiophrenic angle, $38 \%$; at the level of the right auricle, $4.3 \%$; at the level of the left auricle, $5.4 \%$; and at the level of the aortic arch, $1 \%$.

Daumet (1954) found three cases out of four in the right cardiophrenic angle. Key (1954) found two cases in the posterior and two in the anterior mediastinum.

Roche (1954) contended that the definition of pleuro-pericardial cyst must cover not only the histological structure of the pleura and of the pericardium but also the location in the cardiophrenic angle. He added that cysts of that type can be found in the anteromedian as well as in the superior mediastinum.

In 1950 Wellens and Swartenbroekx reported two cases in the antero-inferior mediastinum, one on the right side, the other on the left.

In a review of 29 cases Lillie, McDonald, and Clagett (1950) found 17 cysts in the right cardiophrenic angle, seven cysts pedunculated here, and only five cysts higher in the middle mediastinum. Flavell (1957) found the cyst to be located in the right cardiophrenic angle in $70 \%$ of his cases. Morrison (1958) reports 12 such cases out of 13, and Good (1950) found the right cardiophrenic angle to be the site of the cyst in $66 \%$ of his cases.

Out of 20 cysts described by Le Roux (1959), 13 were in the right cardiophrenic angle and six in the left; in one patient the opacity was visible on both sides of the cardiac shadow.

\section{SHAPE AND CONTENT}

The cyst is unilocular, round, or ellipsoid. It may or may not be pedunculated and varies in size. The weight ranges between $100 \mathrm{~g}$. and $300 \mathrm{~g}$. Lam (1947) reported one case where the cyst contained 1 litre of fluid and measured $25 \times 37.5 \mathrm{~cm}$.

The fluid is a transudate. The 'water' is clear and has been compared to rock-water, whence the name 'spring water cyst'. In some cases, however, the tuid is yellow (Roche, 1954).

\section{AETIOLOGY}

Lambert (1940) has described the origin of these cysts. Mostly they are situated in the cardiophrenic angle and covered with unilaminar endothelium. Churchill and Mallory (1937) and Drash and Hyer (1950) call this mesothelium. The blood supply comes from the pericardium. In the early embryonic period the mesoderm develops next to the chorda with the resulting formation of cavities called coelomic cavities. From these originate the pericardial, pleural, and peritoneal cavities. One defect in the fusion of one or several lacunae which go to make the coelomic cavities will result in the genesis of pleuro-pericardial cysts. The mesodermal cells around the coelom become epithelial cells and build up the basis for the serous endothelial cells.

Initially cuboid in shape they flatten out subsequently. The pleura and the pericardium develop from the same coelomic cavity: that is why Herbig, Ganz, and Vieten (1952) believe that the term 'pleuro-pericardial cyst' gives the most accurate description of the tumour.

Ringertz and Lidholm (1956) contended that there may sometimes be a connexion between the cyst and the pericardium, so that it becomes difficult to tell whether the resulting growth is a true cyst or a diverticulum. Some authors believe pericardial cysts and pericardial diverticula to be one and the same thing.

Brown and Dunn (1951), and later Flavell (1957), mentioned the possible existence of a narrow connexion through which the fluid might be forced from the pericardium into the cyst, and vice versa.

Lillie et al. (1950) placed emphasis on the role that persistence of the ventral parietal recess of the pericardial coelom may play in the development of pericardial coelomic cysts and diverticula of the pericardium.

\section{ANATOMO-PATHOLOGY}

The cyst wall has a simple histological structure, a continuous endothelial layer with juxtaposed cuboid and flattened epithelial cells, which covers a thin fibrous wall of loose connective tissue, poorly irrigated and containing no muscular fibres, a fact that Daumet (1954) stresses as being typical.

\section{CLINICAL FINDINGS}

Cysts of this type are generally detected on the occasion of large-scale radiological examinations. The patients never complain and the 'ideal' age group is said to be the forties. The congenital cyst thus remains silent until the patient is in his regressive period. Key (1954) reports one case in a 23-yearold patient, and Vanpeperstraete (1956) another in a recruit aged 18 . Cysts are found more commonly in men than in women. An explanation of this is 
that men are more often subjected to routine mass radiological examinations than women.

Out of their 91 cases collected from the literature, Grundmann et al. (1955) found $61.5 \%$ men and $38.5 \%$ women.

Roche (1957) had three men out of four cases, Ringertz and Lidholm (1956) four out of six, and Le Roux (1959) 12 out of 20.

When the cyst is not found by chance, it is most often revealed because of its growing size and resulting pressure disorders. The commonest symptoms are dyspnoea, coughing, atelectasis, venous obstruction, retrosternal pain, pulse alterations, palpitations, pain at the level of the cardiac apex, fullness, and difficult eating.

Grundmann et al. (1955) found that of their 91 patients $38(41.7 \%)$ had no complaints and 53 $(58.3 \%)$ complained of some disorder.

Of these 53 patients, the complaint was pleuropulmonary in $24(45 \cdot 2 \%)$, cardial in $15(28 \cdot 3 \%)$, and undefined in $14(26.5 \%)$.

Mathey (quoted by Savinel, 1951) found pericardial cysts by accident following a fit of angina in one patient and following an attack of asthma in another: Leahy and Culver (1947) found one case following haemoptysis.

\section{DIAGNOSIS}

Our best auxiliary aid is radiological examination: initially a simple screening which should subsequently be completed by frontal and profile pictures, tomography, bronchography, and occasionally kymography. When screening indicates that a tumour is present in the right or left supradiaphragmatic area in close connexion with the heart shadow, a pericardial cyst should be suspected. An apparent separation between the heart shadow and the tumour is possible (case 3 ), due to a small distance between the pericardium and the heart muscle, and the tumour can even prove to have a mobility independent of the heart.

Malignant tumours are situated higher up in the mediastinum and are most common in the posterior mediastinum. Thyroid or thymus cysts are found in the antero-superior mediastinum.

Pleuro-pericardial cysts are distinctly outlined and sometimes have the shape of a bullet. Where the development of the cyst is followed radiologically, only a very little change in volume will be noticed. Gernez-Rieux and Savinel (1951) found an enlargement after four years, Morel, Poggioli, and Bernard (1952) after three years.

The growth shows as a definite radiological opacity; malignant cysts are more indefinite in outline and consistency.
Wellens and Swartenbroekx (1950) believed that it is typical that the tumour does not change in position with respiratory movements. Roche (1957) contended that it is normal for the tumour to follow the diaphragmatic movements.

Posturing the patient in Trendelenburg's position may displace the cyst, and so may a pneumothorax or a pneumoperitoneum. A pneumothorax will also reveal whether the tumour has an intra- or extrapulmonary location. Diagnostically these tests are worthless or useless, as well as a pneumomediastinum, which moreover is not without danger. We have seen a haemopericardium with cardiac tamponade from laceration of the myocardium during an attempt to install a diagnostic pneumomediastinum for a tumour which obviously was a pericardial cyst.

A transparietal puncture of the cyst may be performed, but this is not devoid of danger (Lippert, Potozky, and Furman, 1951). Roche (1957) reports one pneumothorax out of five punctures. Thoracoscopy may also be useful and a puncture may be done on that occasion.

Radiologically, a diaphragmatic hernia can be excluded by the administration of a barium meal, and a plunging goitre by appropriate tests with radioactive iodine.

Thoracotomy will provide the final diagnosis, and the cyst should subsequently be examined histologically.

\section{DIFFERENTIAL DIAGNOSIS}

Apart from the possibility of congenital cysts in the thorax, it will be necessary to eliminate hernias of the fissura pericardiacoperitonealis (Morgagni) and the trigonum sternocostale diaphragmatis (Larrey).

A more difficult differential diagnosis is between pleuro-pericardial cyst and cystic pericardial lymphangioma. Aspiration will reveal lymphocytes in a lymphangioma, and histologically the cyst wall is thicker, contains blood vessels, lymphocytes, and very thin fibres. In addition, the cyst is multilocular.

In the anteromedian mediastinum the possibility of a haemangioma should also be borne in mind, though this occurs more frequently in children. A diagnosis of this kind cannot be accepted unless the only auxiliary, angiocardiography, is positive (Eschapasse, Moreau, Poggioli, and Bollinelli, 1958). Angiocardiography will also eliminate aneurysm (Davis, Dorsey, and Scanlon, 1953).

\section{COMPLICATIONS}

Some danger lies in the pressure disorders which occur when the tumour grows in size: pressure on 
the heart which is affected directly or through the vagus, and pressure on the bronchi with resulting atelectasis of the pulmonary lobes.

Following aspiration there is a danger of infection, so that this should be avoided as a general rule.

As to the benign nature of these cysts, all authors reviewed by us are in complete agreement: no degeneration or recurrence of simple cysts has ever been observed.

\section{THERAPY}

The only therapy consists in surgical removal of the cyst. The operation is simple. The cyst can be extirpated easily, and post-operatively the patient almost at once experiences a marked improvement in breathing. Patients who have complained of asthmatic attacks often find that these have been relieved.

\section{SUMMARY}

With reference to three cases from their own experience the authors reviewed the literature on congenital pleuro-pericardial cysts. Such congenital forms are an infrequent occurrence, especially the location of the cyst in one of the cases discussed, $v i z$, in the antero-superior mediastinum. They stress the possibility of a separation, radiologically, between the heart shadow and the tumour, and of a certain mobility, independent of the heart.

\section{REFERENCES}

Anderson, W. A. D. (1953). Pathology, 2nd ed. Mosby, St. Louis. Barrett, N. R., and Barnard, W. G. (1945). Brit. J. Surg., 32, 447. Brown, R. B., and Dunn, R. G. (1951). U.S. armed Forces med. J., 2, 1651 .

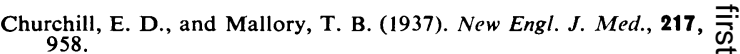

D'Abreu, A. L. (1937). Brit. J. Surg., 25, 317.

Daumet, P. (1954). J. franç. Méd. Chir. thor., 8, 490.

Davis, C., Dorsey, J., and Scanlon, E. (1953). A.M.A. Arch. Surg., $67,110$.

Drash, E. C., and Hyer, H. J. (1950). J. thorac. Surg., 19, 755.

Eschapasse, H., Moreau, G. Poggioli, J., and Bollinelli, R. (1958) Le poumon et le Coeur, 14, 499.

Flavell, G. (1957). An Introduction to Chest Surgery. Oxford University Press, London.

Gernez-Rieux, C., and Savinel, E. (1951). J. frans. Méd. Chir. thor., $5,474$.

Good, C. A. (1950). Chicago med. Soc. Bull., 53, 51.

Greenfield, I., Steinberg, I., and Touroff, A. S. W. (1943). J. thorac Surg., 12, 495.

Grundmann, G., Fischer, R., and Griesser, G. (1955). Thoraxchirurgie, 2, 492.

Herbig, H., Ganz, P., and Vieten, H. (1952). Ergebn. Chir. Orthop., 37, 224.

Jeaubert de Beaujeu, M. (1945). Les Kystes Intrathoraciques Pleuropéricardiques. Thèse, Lyon.

Key, J. A. (1954). Surg. Clin. N. Amer., 34, 959.

Lam, C. R. (1947). Radiology, 48, 239.

Lambert, A. V. S. (1940). J. thorac. Surg., 10, 1.

Leahy, L. J., and Culver, G. J. (1947). Ibid., 16, 695.

Le Roux, B. T. (1959). Thorax. 14, 27.

Lillie, W. I. McDonald, J. R., and Clagett, O. T. (1950). J. thorac. Surg., 20, 494.

Lippert, K. M., Potozky, H., and Furman, I. K. (1951). A.M.A. Arch. intern. Med., 88, 378.

Loehr, W. M. (1952). Amer. J. Radiol., 68, 584.

Morel, L., Poggioli, J., and Bernard, E. (1952). Toulouse méd., 233. Morrison (1958). Thorax, 13, 294.

Nelson, T. G., Shefts, L. M., and Bowers, W. F. (1957). Dis. Chest, 32, 123 .

Nylander, P. E. A., and Viikari, S. J. (1948). Ann. chir. gynaec. Fenn., 37, 99.

Ringertz, N., and Lidholm, S. O. (1956). J. thorac. Surg., 31, 458.

Roche, G. (1954). J. franc. Méd. Chir. thor., 8, 449.

Roche, L. (1957). In Techniques et Thórapeutiques en Pneumonologie (série 2), p. 115. (Hôpital Bichat). Expansion Scient ifique Française, Paris.

Savinel, E. (1951). Les Kystes Pleuropéricardiques. Thèse, Lille.

Schlumberger, H. G. (1951). Tumors of the Mediastinum. In Atlas of Tumor Pathology, Sect. 5, Fasc. 18. Armed Forces Institute of Pathology, Washington.

Vanpeperstraete, F. (1956). Acta chir. belg., 55, 624.

Wellens, P.. and Swartenbroekx, A. (1950). J. belge Radiol., 33, 27. 